Bảng 6: Kêt quả phát hiện kháng thê, RNA của virus Zika và CHIK

\begin{tabular}{|c|c|c|c|c|c|c|}
\hline \multirow{2}{*}{ Giá trị Nhóm } & \multicolumn{3}{c|}{ Zika } & \multicolumn{3}{c|}{ CHIK } \\
\cline { 2 - 7 } & IgM & IgG & RNA & IgM & IgG & RNA \\
\hline Dương tính & 0 & 0 & 0 & 0 & 0 & 0 \\
\hline Âm tính & 50 & 50 & 50 & 50 & 50 & 50 \\
\hline Khác & 0 & 0 & 0 & 0 & 0 & 0 \\
\hline Tổng & $\mathbf{5 0}$ & $\mathbf{5 0}$ & $\mathbf{5 0}$ & $\mathbf{5 0}$ & $\mathbf{5 0}$ & $\mathbf{5 0}$ \\
\hline
\end{tabular}

Nhận xét: Để đánh giá sâu hơn về tình trạng gây bểnh sốt xuất huyết ở Nha Trang, các thử nghiệm về sinh học phân tử được tiến hành với hai mầm bệnh chủ yếu ngoài virus dengue, đó là virus Zika và Virus Chikungunya. Kết quả bảng 6 cho thấy, không có bệnh nhân nào phản ứng với các nghiệm pháp, hay nói cách khác, chưa phát hiện mầm bệnh Zika và CHIK trong cộng đồng sốt xuất huyết ở Nha Trang.

\section{KẾT LUÂ̂N}

Qua nghiên cứu trên 100 bệnh nhân sốt xuất huyết tại Nha Trang, kết quả cho thấy, nhóm đối tượng mắc bệnh chủ yếu ở trẻ em $(21 \%)$ và người già (20\%). Nguyên nhân gây bệnh sốt xuất huyết, phát hiện có $9 \%$ dương tính với virus Dengue, trong khi đó hoàn toàn âm tính với hai virus Zika và Chikungunya.

\section{TÀI LIẸU THAM KHẢO}

1. Endy TP, Chunsuttiwat $S$, Nisalak A, Libraty DH, Green S, Rothman AL, et al. Epidemiology of inapparent and symptomatic acute dengue virus infection: a prospective study of primary school children in Kamphaeng Phet, Thailand. American journal of epidemiology. 2002; 156(1):40-51.

2. Nisalak A, Endy TP, Nimmannitya $S$, Kalayanarooj S, Scott RM, Burke DS, et al. Serotype-specific dengue virus circulation and dengue disease in Bangkok, Thailand from 1973 to 1999. The American journal of tropical medicine and hygiene. 2003; 68(2):191-202.

3. Flipse J, Diosa-Toro MA, Hoornweg TE, Van De Pol DP, Urcuqui-Inchima S, Smit JM. Antibody-dependent enhancement of dengue virus infection in primary human macrophages; balancing higher fusion against antiviral responses. Scientific reports. 2016; 6:29201.

4. Fried $J R$, Gibbons $R V$, Kalayanarooj $S$, Thomas SJ, Srikiatkhachorn A, Yoon I-K, et al. Serotype-specific differences in the risk of dengue hemorrhagic fever: an analysis of data collected in Bangkok, Thailand from 1994 to 2006. PLoS neglected tropical diseases. 2010; 4(3):e617.

5. Chan K-S, Chang J-S, Chang $K$, Lin C-C, Huang $\mathbf{J}-\mathbf{H}$, Lin $\mathbf{W}-\mathbf{R}$, et al. Effect of serotypes on clinical manifestations of dengue fever in adults. Journal of microbiology, immunology, and infection. 2009; 42(6):471-8.

\title{
PHẪU THUẬT NộI SOI TẠO HÌNH KHÚC NỐI BỂ THẬN NIỆU QUẢN THEO NGUYÊN TẮC FINNEY
}

\section{TÓM TẮT}

Đặt vấn đề: Báo cáo này lần đầu tiên giới thiệu kỹ thuật nội soi tạo hình khúc nối bể thận niệu quản (KNBTNQQ) theo nguyên tắc Finney. Phương pháp: Hồi cứu 1 ca bệnh và tổng quan y văn. Kết quả: Bệnh nhân (BN) nam 4 tuổi, đưỡc chẩn đoán hẹp KNंBTNQ trái có chỉ định điều trị phẫu thuật. Chúng tối phẫu thuật nội soi ổ bụng, nhận thấy niệu quản (NQ) trái bám cao ở vị trí giữa bể thận (BT) gây gập góc làm tắc KNBTNQ. BN được rach 1 đướng mờ BT từ dưới chỗ nối BTNQ đi qua thành dưới khúc nối sang thành NQ đối diện BT. Tạo hình KNBTNQ theo nguyên

*Bệnh viện đa khoa Saint Paul

Chịu trách nhiệm chính: Trần Ngọc Sơn

Email: drtranson@yahoo.com

Ngày nhận bài: 26.10.2020

Ngày phản biện khoa học: 27.11.2020

Ngày duyệt bài: 10.12 .2020

\section{Trần Ngọc Sơn*, Dương Văn Mai*}

tắc Finney bằng cách khâu nối mép NQ với mép BT chỗ vừa mở, có đă̆t 1 dẫn lưu NQ-BT ra da. Thời gian phẫu thuật 50 phút, không có tai biến trong mổ. Sau mổ BN diễn biến ổn định, dẫn lưu được rút sau 6 ngày, thời gian nằm viện sau mổ 7 ngày.Theo dõi 8 tháng BN không có triệu chứng, siêu âm bể thận bình thường. Kết luận: Phẫu thuật nội soi tạo hình KNBTNQ theo nguyên tắc Finney là an toàn, đớn giản, thời gian phẫu thuật ngắn, có thể là một lựa chọn tốt trong điều trị tắc KNBTNQ ở trẻ em trong trường hợp niệu quản bám cao.

Tư khóa: phẫu thuật nội soi, tạo hình khúc nối bể thận niệu quản, nguyên tắc Finney

\section{SUMMARY \\ LAPAROSCOPIC PYELOPLASTY BY FINNEY'S PRINCIPLE}

Introduction: In this report, we described a new technique of laparoscopic pyeloplasty by Finney's principle. Methods: a case report and review of the 
literature. Results: A four-year-old boy was indicated for surgical repair for left pyelo-ureteral junction (PUJ) obstruction. Laparoscopic surgery was performed and intraoperatively we found a high left ureteral insertion to the middle of the pyelon, causing kinking and obstruction of the PUJ. A incision was made on the pyelon, started below the PUJ and continued on the lower wall of the PUJ to the adjancent ureteral wall. A pyeloplasty by Finney's principle was performed as the opened wall of the pyelon was sutured to the adjacent opened wall of the ureter. A percutatneous pyeloureteral drain was placed. The operative duration was 50 minutes. There was no intraoperative complication. The patient recovered uneventfully, the drain was taken out on $6^{\text {th }}$ day and he was discharged on $7^{\text {th }}$ day after the operation. At the follow up of 8 months, the patient was asymptomatic, ultrasound showed normal pyelon. Conclusions: Laparosopic pyeloplasty by Finney's principle is safe, simple with short operative time and can be a good choice in surgical repair for PUJ obstruction with high ureteral insertion.

Keywords: pyelo-ureteral junction obstruction, laparoscopic pyeloplasty, Finney's principle

\section{I. ĐĂTT VẤN ĐỀ}

Hẹp KNBTNQ được định nghĩa như sự giảm lưu thông nước tiểu từ bể thận xuống niệu quản, gây ứ nước thận và có khả năng gây ra suy giảm chức năng thận. Dị dạng này có thể gặp ở mọi lứa tuổi ở trẻ em và gặp nhiều nhất trong thận ứ nước ở trẻ sơ sinh. Tỷ lệ mắc bệnh $1 / 1500$ trẻ sinh ra, nam/nữ $=2 / 1$. Bên trái $(60 \%)$ nhiều hơn bên phải. Trước khi có chẩn đoán siêu âm trước sinh, các $B N$ thường không biểu hiện triệu chứng đặc hiệu, được phát hiện tình cờ qua thăm khám, một số BN biểu hiện dưới dạng có khối u ổ bụng, đau bụng, nhiễm trùng tiết niệu, tiểu máu. Siêu âm là phương tiện về hình ảnh đầu tiên được sử dụng để chẩn đoán về tình trạng thận ứ nước, chụp cắt lớp vi tính (CLVT) dựng hình hệ tiết niệu, chụp xạ hình thận giúp chẩn đoán xác định và tiên lượng bệnh [3].

Có nhiều phương pháp tạo hình khúc nối bể thận niệu quản được sử dụng như phẫu thuật cắt bỏ đoạn hẹp và nối bể thận niệu quản (Anderson-Hynes), tạo hình BT-NQ kiểu Y-V, kỹ thuật tạo hình mảnh ghép xoắn (Spiral flap) của Culp và De Weerd [7]... Theo một số tác giả, kỹ thuật cắt nối tạo hình niệu quản có ưu điểm cắt bỏ đoạn niệu quản hẹp bất thường, tuy nhiên kỹ thuật cần phải cắt nối tạo hình phức tạp, đôi khi trong phẫu thuật gặp phải BN có bế thận sâu vào rốn thận, hoặc chiều dài niệu quản ngắn thì vấn đề tạo hình KNBTNQ lại rất khó khăn, những trường hợp như vậy thì một kỹ thuật tạo hình BT-NQ không cắt tạo hình bể thận có thể lựa chọn giải quyết vấn đề này. Trong trường hợp niệu quản bám cao, ứng dụng nguyên tắc Finney trong tạo hình môn vị [2], với 1 đường từ bể thận dưới chỗ nối BTNQ đi qua thành dưới khúc nối sang thành niệu quản đối diện bề thận, sau đó khâu hai mép niệu quản với hai mép của bể thận, như vậy chiều dài niệu quản không bị co kéo, trong khi đó vẫn đảm bảo tạo hình khúc nối BTNQ đường kính lớn hơn $1 \mathrm{~cm}$. Theo tìm hiểu của chúng tôi cho đến nay mới có 1 vài nghiên cứu ứng dụng nguyên tắc Finney trong mổ mở tạo hình KNBTNQ và chưa có báo cáo nào về phẫu thuật nội soi sử dụng nguyên tắc này. Chúng tôi báo cáo ca bệnh đầu tiên được phấu thuật nội soi tạo hình KNBTNQ theo nguyên tắc tạo hình môn vị của Finney.

\section{BÁO CÁO CA BỆNH}

BN (BN) nam 4 tuổi, đau bụng 1 ngày trước khi vào viện. Khám lâm sàng thây tình trạng $B N$ tỉnh táo, đau bụng hạ sườn trái, ấn hạ sườn trái đau tức, chạm thận âm tính. Siêu âm, CT scanner hình ảnh ứ nước thận trái do hẹp KNBTNQ trái (Hình 1), bể thận trái giãn $35 \mathrm{~mm}$. Chụp xạ hình thận thấy chức năng lọc cầu thận trái giảm còn $38 \%$, có tắc nghẽn đường bài xuất. BN được chẩn đoán ứ nước thận trái do hẹp KNBTNQ và chỉ định phẫu thuật nội soi qua phúc mạc để tạo hình KNBTNQ.

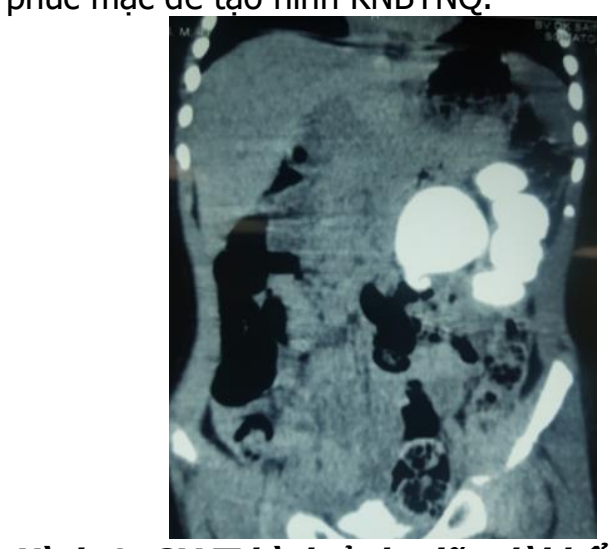

Hình 1: CLVT hình ảnh giân đài bể thận trái của $B N$

$\mathrm{BN}$ được đặt nằm nghiêng phải 30 độ trên bàn mổ. Chúng tôi đăt 1 trocar $11 \mathrm{~mm}$ qua rốn và 2 trocar $5,5 \mathrm{~mm}$ ở hố chậu trái và đường giữa vùng thượng vị. Sau khi bộc lộ thận và KNBTNQ trái, quan sát thấy bể thận trái giãn to, niệu quản trái bám cao gây gập góc. Chúng tôi mở bể thận 1 đường từ phía dưới KNBTNQ đi qua thành dưới khúc nối sang niệu quản với tổng chiều dài $2,5 \mathrm{~cm}$ (1 nửa phía bể thận và 1 nửa phía niệu quản - Hình 2 A). Sau đó khâu mép sau chỗ mở của bể thận với mép sau của niệu quản (Hình 2 B), tiếp đó khâu mép trước của bể thận với mép 
trước niệu quản bằng chỉ PDS 5.0 khâu vắt (Hình 2C). Trước khi khâu kín hoàn toàn có đặt 1 dẫn lưu NQ-BT ra da. Thời gian phẫu thuật 50 phút, không có tai biến trong mổ hay biến chứng sau mổ. Sau mổ BN phục hồi tốt, ăn lại đường miệng ngày thứ 2 , dẫn lưu được rút ngày thứ 6 sau mổ, thời gian nằm viện sau mổ là 7 ngày. Khám lại sau ra viện 1 tháng BN không đau bụng, siêu âm bể thân trái $11 \mathrm{~mm}$.Theo dõi 8 tháng sau mổ BN không đau bụng, siêu âm bể thận trái bình thường.

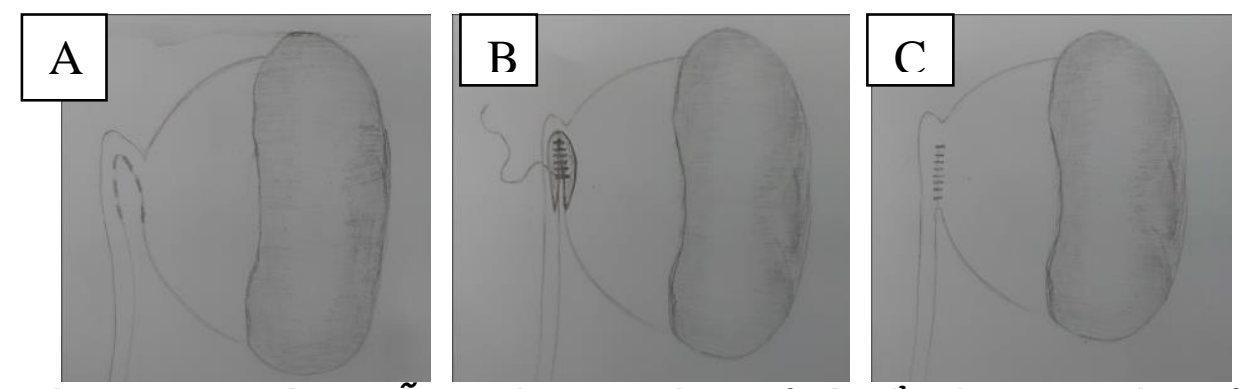

Hình 2: Lược trinh phẫu thuật: A: đường mở từ bể thân sang niệu quản;
B: khâu mép sau BT-NQ; C: sau khi khâu mép trước BT-NQ

\section{BÀN LUÂN}

Trước đây, một số tác giả đưa ra giải pháp nội soi niệu quản mở chỗ hẹp sau đó đặt sonde niệu quản bể thận ra da, lưu sonde khoảng 5 tuần. Tác giả Tawfied nội soi đặt sonde BT-NQ dưới hướng dẫn của siêu âm hoặc màn huỳnh quang giúp định hướng tốt hơn, đánh giá được xem sonde đã qua chổ hẹp chưa, và giảm nguy cơ tai biến trong quá trình phẫu thuật, tuy vậy những phương pháp này tỷ lệ thành công không được cao nên ngày nay ít được áp dụng $[3,7]$

Kể từ khi được mô tả vào năm 1949, phương pháp tạo hình khúc nối BTNQ theo Anderson Hynes đã được nhiều tác giả chứng minh là khả thi và có thể áp dụng rộng rãi trong điều trị hẹp khúc nối BTNQ ở trẻ em [3].

Tác giả Diamond cho rằng kỹ thuâtt $\mathrm{V}$ flap hiệu quả trong những trường hợp niệu quản bám cao vì vạt chữ $V$ có thể làm cho đoạn niệu quản dài thêm được $1-2 \mathrm{~cm}$ mà không cần giải phóng niệu quản xuống sát bàng quang giúp bảo tồn tốt hơn mạch máu nuôi niệu quản. Mặt khác, trong niệu quản bám cao, niệu quản bị gập góc gây tắc KNBTNQ mà không phải nguyên nhân do hẹp niệu quản nội tại, vì vậy việc cắt bỏ đoạn niệu quản là không thực sự cần thiết [1].

Lane (2005) [6] đã báo cáo phương pháp chuyển vị KNBTNQ vẫn giữ lại đoạn niệu quản chố nối chỉ chuyển từ cao xuống thấp để đoạn niệu quản không bị gập góc. Tuy vậy kỹ thuật này vấn cắt rời KNBTNQ khỏi bể thận và phải làm lại một miệng nối hoàn toàn mới.

Tạo hình bể thân kiểu Y-V của Foley được sử dụng cho các trường hợp khúc nối bể thận-niệu quản hẹp vừa phải, bể thận giãn ít vẫn còn hình phễu, đặc biệt phù hợp với niệu quản đổ cao cho tỷ lệ thành công cao. Tác giả Fenger thực hiện 1 đường rạch dọc ở mặt trước bể thận qua niệu quản đoạn hẹp sau đó tiến hành khâu ngang làm rộng vị trí hẹp cũng cho kết quả tốt [7].

Tác già Mesrobian [4] tiến hành phẩu thuật nối tắt (by-pass) BT-NQ: thực hiện 1 đường rạch ở bể thận - 1 đường rạch ở niệu quản khoảng mà không qua đoạn hẹp, rồi nối BT với NQ. Kỹ thuật này không cắt bỏ niệu quản, giữ được chiều nhu động tự nhiên từ bể thận xuống niệu quản. Đến nằm 2013 tác giả Paul thực hiện nội soi nối tắt tạo hình $\mathrm{BT}-\mathrm{NQ}$ với nguyên tắc trền để điều trị thận ứ nước do niệu quản bám cao cho một trẻ nam 3 tháng tuổi. Cả 2 báo cáo bước đâu đều đạt được kết quả tốt [5].

Phương pháp tạo hình KNBTNQ theo nguyên tắc Finney lần đâu tiên được mô tả bởi tác giả Von Richkenberg năm 1921 với 22 BN được phẫu thuật mở, tác giả khuyến cáo kỹ thuật này đặc biệt phù hợp với BN có niệu quản bám cao. Đển nằm 1951 tác giả Schwazrtz báo cáo phẫu thuật cho 2 BN người lớn thành công. Năm 1996 tác giả F. Ikoma thực hiện phẫu thuật mở cho 8 BN nhi có kết quả tốt $100 \%$, thời gian để dẫn lưu từ 2-5 ngày. Về phẫu thuật nội soi tạo hình KNBTNQ theo nguyên tắc Finney theo tìm hiểu của chúng tôi chưa có tác giả nào công bố [8].

Theo một số tác giả, phẫu thuật theo nguyên tắc Finney là thuận theo cấu trúc giải phấu tự nhiên từ bể thận xuống niệu quản, vì phẩu thuật không cắt bỏ cấu trúc giải phấu BT-NQ. Tác giả Von Lichkenberg không ủng hộ việc cắt bỏ đoạn niệu quản vì như vậy sẽ làm mất tính liên tục cấu trúc giải phẫu niệu quản. Tác giả Ward tin rằng những phẫu thuật bảo tồn thận như Von Lichkenberg là lựa chọn tốt giúp giữ được cấu 
trúc giải phẫu từ $\mathrm{BT}-\mathrm{NQ}$ được tự nhiên, kết quả lâu dài sẽ tốt. Hơn nữa, kỹ thuật tạo hình theo nguyên tắc Finney, miệng nối niệu quản theo chiều dọc, do vậy vòng tròn niệu quản sẽ tránh được tình trang xơ hẹp hết cả vòng tròn chu vi niệu quản chỗ nối, hạn chế tối thiểu nguy cơ hẹp miệng nối sau mổ [8].

Trong ca bệnh cụ thể của chúng tôi, thời gian phẫu thuật nội soi tạo hình KNBTNQ là 50 phút. Do kỹ thuật rạch 1 đường từ bể thận qua khúc nối sang niệu quản sau đó khâu lại, thao tác không quá phức tạp nên thời gian phẫu thuật của chúng tôi tương đối ngắn hơn so với các báo cáo kỹ thuật tạo hình KNBTNQ khác. Trong kỹ thuật tạo hình KNBTNQ theo nguyên tắc Finney, vì không cắt bỏ niệu quản mà chỉ mở niệu quản bể thận qua khúc nối nên chúng tôi thấy rằng ngoài ưu điểm giữ tính giải phẫu liên tục $\mathrm{BT}-\mathrm{NQ}$ thì sau khi tạo hình miệng nối sẽ đảm bảo không bị căng, khổng có nguy cơ bị xoắn vặn miệng nối (so với các kỹ thuật có cắt rời KNBTNQ), ít nguy cơ bị hẹp, giữ được nguồn cấp máu nuôi dưỡng niệu quản từ các nhánh của động mạch thận phía bể thận. So với kỹ thuật Fenger thì miệng nối trong kỹ thuật của chúng tôi có thể tạo rộng hơn và không bị căng. So với tạo hình Y-V theo Foley thì kỹ thuật của chúng tôi đơn giản, dễ thực hiện hơn với phẫu thuật nội soi. Tạo hình theo nguyên tắc Finney cũng sẽ không để lại đoạn NQ còn bị gập tắc với các nguy cơ tiểm ẩn (nhiễm trùng, sỏi tiết niệu) như kỹ thuật nối tắt BT-NQ kiểu by-pass.

\section{KẾT LUẬN}

Phương pháp phẫu thuật tạo hình KNBTNQ theo nguyên tắc Finney là an toàn, tương đối đơn giản, có thể là một lựa chọn kỹ thuật khả thi trong điều trị thận ứ nước ở trẻ em do niệu quản bám cao.

\section{TÀI LIÊU THAM KHẢO}

1. Diamond D. A., Nguyen H. T. (2001). Dismembered V-flap pyeloplasty. J Urol, 166: 233-5

2. John M. T. Finney. (1926). The surgery of gastric and duodenal ulcer. Bulletin of the New York Academy of Medicine, 2: 546-579

3. Joel F. Koenig, Douglas E. Coplen. (2017). Ureteral obstruction and malformations. Holcomb and Ashcraft's Pediatric Surgery, 7: 837

4. H. G Mesrobian. (2009). Bypass pyeloplasty: description of a procedure and initial results. J Pediatr Urol, 5: 34-6

5. Noh Paul H, Anish K Shah. (2013). Laparoscopic bypass pyeloureterostomy. Journal of Pediatric Urology, 9: 51-53

6. Lane S Palmer, Juan Miguel Proano, Jeffrey S Palmer. (2005). Renal pelvis cuff pyeloplasty for ureteropelvic Juntion obtruction for the high inserting ureter: an initial experience. The Journal of Urology, 174: 1088-1090

7. E. R Tawfiek, J. B Liu, D. H Bagley. (1998). Ureteroscopic treatment of ureteropelvic junction obstruction. J Urol, 160: 1643-6; discussion 1646-7

8. Von Lichtenberg. (1921). Technisches zur Ureteropyeloanastomose. Amer. Med. Assoc., 284: 743

\title{
THỰC TRẠG NHU CẦU HỖ TRỢ CHĂM SÓC NGƯỜI BÊNNH UNG THƯ VÚ TẠI BỆNH VIÊ̂N K NĂM 2020 VÀ MộT SỐ YẾU TỐ LIÊN QUAN.
}

\author{
Vương Hồng Hạnh*, Nguyễn Hải Anh**, Hoàng Đức Thành*,
} Lưu Quang Hội*, Nguyễn Thị Thu Thủy*.

\section{TÓM TẮT}

Mục tiêu: Mô tả một số đặc điểm lâm sàng và điều trị của người bệnh ung thư vú (UTV) và phân tích một số yếu tố liên quan đến nhu cầu chăm sóc người bệnh ung thư vú tại Khoa Điều trị theo yêu cầu, Bệnh viện K (cơ sở Quán sứ) năm 2020. Phương pháp nghiên cứu: Nghiên cứu mô tả cắt ngang. Kết quả: Tuổi trung bình của người bệnh là 55 , chủ yếu ở

\footnotetext{
*Bệnh viện $K$

**Đại học Thăng Long

Chịu trách nhiệm chính: Vương Hồng Hạnh

Email: honghanh.vuong@bvk.org.vn

Ngày nhận bài: 27.10 .2020

Ngày phản biên khoa họ: 30.11.2020

Ngày duyệt bài: 9.12.2020
}

nhóm tuổi từ 40-59 (56\%). Nghiên cứu ghi nhân người bênh ung thư vú phần lớn ở giai đoạn IA và IİA (64\%). Phác đồ được sử dụng nhiều nhất là phác đồ chứa anthracyclin và cyclophosphamide (63\%). Nhu cầu cao nhất được ngưới bệnh UTV nhận định là nhu cầu về tâm lý (56\%). Không sự khác biệt có ý nghĩa thống kê giữa các nhu cầu với tuổi của người bênhUTV. Nhu cầu thể chất có sư khác biệt có ý nghĩa thống kê giữa các phân nhóm giai đoạn bệnh $(p=0,025)$. Kết luâan: Điều dưỡng cần lưu ý tới các nhu cầu chăm sóc của người bệnh UTV, đặc biệtnhu câuu hỗ trợ tâm lý và nhu cầu thể chất ở người bệnh giai đoạn tiến xa.

Tư khóa: Ung thư vú, điều dưỡng, chăm sóc người bệnh, nhu cầu người bệnh.

\section{SUMMARY \\ THE CURRENT SITUATION OF BREAST}

